Lindsay, C., Findlay, P., McQuarrie, J., Bennie, M., Corcoran, E. D. and Van Der Meer, R. (2017) Collaborative Innovation, New Technologies, and Work Redesign. Public Administration Review. doi:10.1111/puar.12843

Colin Lindsay

Scottish Centre for Employment Research, University of Strathclyde, Glasgow G40QU, United Kingdom, colin.lindsay@strath.ac.uk

Patricia Findlay

Scottish Centre for Employment Research, University of Strathclyde, Glasgow G40QU, United Kingdom, patricia.findlsay@strath.ac.uk

Johanna McQuarrie

Scottish Centre for Employment Research, University of Strathclyde, Glasgow G40QU, United Kingdom, j.mcquarrie@strath.ac.uk

Marion Bennie

Strathclyde Institute of Pharmacy and Biomedical Sciences, University of Strathclyde, Glasgow G40RE, United Kingdom, marion.bennie@strath.ac.uk

Emma Dunlop Corcoran

Strathclyde Institute of Pharmacy and Biomedical Sciences, University of Strathclyde, Glasgow G40RE, United Kingdom, emma.d.corcoran@strath.ac.uk

Robert Van Der Meer 
Department of Management Science, University of Strathclyde, Glasgow G40QU, United Kingdom, robert.van-der-meer@strath.ac.uk

\section{Author biographies}

Colin Lindsay is Reader in Human Resource Management and Deputy Director of the Scottish Centre for Employment Research at the University of Strathclyde. His research addresses workplace innovation and progressive workplace practices, public service management, and the impact of employability policies. He publishes widely in international academic and professional journals on employment-related issues in public services.

Patricia Findlay is Professor of Work and Employment Relations and Director of the Scottish Centre for Employment Research at the University of Strathclyde. Her recent interests span workplace innovation (www.innovatingworks.org.uk), job quality, skills, and employeremployee partnerships. She is the co-editor of "Are Bad Jobs Inevitable? Trends, Determinants and Responses to Job Quality in the Twenty-First Century' (Palgrave Macmillan).

Johanna McQuarrie is a Research Fellow at the Scottish Centre for Employment Research at the University of Strathclyde. Her research addresses employee involvement in innovation, workplace innovation, and job quality, with a current focus on innovation in community pharmacy and in the food and drink sector.

Marion Bennie is a Professor of Pharmacy, Strathclyde Institute of Pharmacy and Biomedical Sciences, and Chief Pharmacist, Public Health and Intelligence, NHS National Services 
Scotland. Her research focuses on real-world clinical data (pharmacoepidemiology) and designing and testing novel health-care intervention models to support innovative clinical practice.

Emma D. Corcoran is a Research Assistant at the Strathclyde Institute of Pharmacy and Biomedical Sciences. Utilizing qualitative research methodologies, her research addresses better use of medicines, innovation in pharmaceutical care services, and patient-reported outcome measures for high-cost cancer medicines.

Robert Van Der Meer is Reader in Management Science at the University of Strathclyde. His research addresses the management of new technology in health-care settings, including both effective technology implementation and workforce impact. He publishes widely in international academic and professional journals focusing on operations, product and services management, and operational research. 


\title{
Collaborative Innovation, New Technologies and Work Redesign
}

\begin{abstract}
Stakeholders agree on the need to promote innovation in work organization in public services. This article deploys the concept of collaborative innovation to discuss employees' and managers' experiences of a major technology-driven work redesign project within National Health Service (NHS) pharmacy services in Scotland. We draw on extant literature on New Public Management (NPM) and collaborative approaches to innovation to frame more than 40 in-depth interviews with managers and employees. We find that key components of collaborative innovation - related to joint problem-solving, inter-disciplinary working and mutual learning - were important to the success of the redesign project and to positive impacts on job quality for some employees. We argue that researchers and policymakers should look beyond NPM-driven models that have dominated some areas of the public innovation literature, to consider the potential added value of collaborative innovation to improving both work and service delivery in the public sector.
\end{abstract}

\section{Practitioner Points}

Collaborative innovation provides a useful alternative to NPM-oriented approaches to promoting innovation in public service workplaces.

Including employees in collaborative decision-making processes can support creative problem solving and innovation. 
Work redesign that creates opportunities for inter-disciplinary boundary spanning and crossfunctional learning can facilitate innovation.

Care needs to be taken that work redesign programs intended to support innovation do not produce the unintended consequence of limiting opportunities for learning and career progression. 


\section{Introduction}

Policymakers, public sector managers and employees accept that there is value in promoting innovative practices in work organization and service delivery in public services. Interest in public sector innovation has intensified given the urgency of multi-faceted, 'wicked' policy problems, an increasingly demanding public, pressure on services as a result of population ageing, and the need to deliver efficiencies in the face of budget austerity (De Vries et al. 2016). Indeed, for some advocates, public innovation is a necessary "intelligent alternative to blind, devolved across-the-board cuts" that might otherwise cause lasting damage to public services and demotivation among employees (Ansell and Torfing 2014, 2).

These challenges are particularly intense in public health services - for example, in the US, concerns about how best to respond to emerging pressures on health services have played out in debates around the sustainability of the Affordable Care Act and Medicaid. In the nations of the UK, where the National Health Service (NHS) accounts for a substantial element of public spending and is required to deliver publicly available healthcare and medicines, a range of reform strategies have been adopted in the hope of achieving greater efficiency and innovation (Lindsay et al. 2014). This article deploys the concept of collaborative innovation, discussed below, to reflect upon employees' and managers' experiences of a major technology-driven work redesign project within NHS pharmacy services in Scotland.

Drawing on recent commentaries by Torfing (2013) and Hartley et al. (2013) the article finds evidence of New Public Management (NPM) influences in the development, management and implementation of the redesign project. However, we suggest that the emergence of collaborative innovation - and especially employee-led initiatives - was vital to the 
realization of the project's objectives and the mitigation of some related problems in relation to work organization and job quality.

Our aim in this article is to demonstrate the value of Torfing (2013) and Hartley et al.'s (2013) conceptualization of NPM-oriented and collaborative approaches as a means distinguishing different (but inevitably, sometimes overlapping) ways of thinking about public sector innovation. We then develop a framework that structures our exploration of employees' experiences of, and influences upon, the aforementioned technology-driven work redesign project. We are therefore drawing upon themes emerging from previous studies of high-level inter-organizational networking, and deploying a framework to explore intraorganizational relationships between managers, different groups of employees and other stakeholders involved in delivering an example of workplace innovation. Like Hartley et al. (2013), we are critical of a managerialist literature that has characterized public sector innovation as synonymous with NPM, while ignoring the latter's constraints and failures. Although based on a single case study, our research suggests that there may be value in further investigation of collaborative approaches to innovation in public workplaces.

Following this introduction, we review NPM-driven and collaborative frameworks for thinking about innovative redesign projects in the public sector. We then describe the context for our research - the introduction of robotics technologies and related work redesign initiatives as part of a fundamental reform of NHS pharmacy distribution services in one area of Scotland. After explaining the research methodology, we present our findings on managers' and employees' experiences, highlighting the decisive role of collaborative innovation in delivering the redesign project, but also acknowledging continuing challenges 
of variable outcomes for individual employees' job quality. Finally, we offer concluding reflections and discuss implications for the promotion of innovative public services.

\section{Innovation and the workplace in public services}

This part of the article connects with NPM-oriented and collaborative approaches to promoting innovation in public services, and discusses the relevance of these literatures to our analysis of employees' experience of work redesign.

\section{From NPM to collaborative innovation}

Hartley et al. (2013) distinguish collaborative approaches from more NPM-oriented innovation in public services, and this seems appropriate given the prominence of the latter model in the public management literature (De Vries et al. 2016). As Hartley et al. (2013) note, central to the NPM understanding of innovation is the idea that practice from the private sector can be transferred to transform public services. Contributors to this literature argue that the necessary antecedents of innovative capacity in the private sector - a strategic commitment to research investment and development in response to competitive pressures; strategic alliances that grow with firm size; and the prioritization of cross-sectoral networking - remain elusive in public service organizations (Sørensen and Torfing 2011). From this perspective NPM and innovation are largely interchangeable, in opposition to traditional public sector practices defined by: a culture of risk aversion; excessive bureaucracy; the absence of mechanisms for disseminating new learning; and structures that reinforce “organizational silos, traditional roles and a lack of cross-cutting co-ordination” (Bason 2010, 16). 
Hartley et al. (2013) challenge directly NPM advocates' claims of an inherent superiority in the private sector's innovative capacity, arguing that across a range of public management and governance regimes, the public sector has been an important facilitator of private enterprises' innovation, and an innovator in its own right (see also Perry and Kraemer 1983; Mazzucato 2013). Whereas Bason $(2010,7)$ suggests that "the very DNA of bureaucratic organizations is resistant to innovation", Hartley et al. (2013) point to the substantial evidence of new service development and innovative work practices that have been driven by public workers and managers. Bekkers et al. $(2011,20)$ previously noted that by the observing the development of public services "a large number of innovations can actually be seen". Pollitt $(2011,38)$ similarly argues that "historically, the public sector has been a major source of innovations in organization, technology and ideas", before citing multiple specific examples.

For these scholars, there are distinctive pressures on public workers and managers to innovate given the needs of an increasingly demanding and diverse client group, a growing acknowledgement of the complexity of 'wicked' policy problems, and the rapid pace of technological and (in the case of health services) medical advances (Bekkers et al. 2011). This would appear to be why many innovations in public services are 'problem-driven' rather than 'incentive-driven' - i.e. innovation often flows not from external performance management, but the need to solve problems "internal to the mission of the agency" and "the intrinsic commitment and professionalism of public sector workers" (Ansell and Torfing 2014, 9). Even standard economic theory on the relationship between firm size and innovation would suggest favourable conditions for innovative activity in the public sector: "large organizations have the resources to invest in innovation and are capable of absorbing 
the costs of innovation failure... this is true across sectors, and there are many more large organizations in the public sector than in the private sector" (Hartley et al. 2013, 823). Finally, a broader public innovation literature points to numerous alternative reform strategies that might transform the reach and impact of public services, with the potential for digital innovation to facilitate personalized services one recurrent theme (Bertot et al. 2016). For example, De Lancer Julnes (2015) reports on innovation strategies deployed by US city governments, noting the increasing dominance of Internet-enabled change programs.

It is also important to acknowledge the "barriers to collaborative innovation inherent to NPM" (Torfing 2013, 302). Critics have argued that NPM promises of dynamism often disintegrate in the face of "the development of an elaborate and rather bureaucratic system of performance management based on large numbers of measures, targets, indicators and benchmarks, which creates gaming behaviours" and "accelerates the production of the kind of detailed bureaucratic rules that NPM was meant to eliminate" (Hartley et al. 2013, 824). Furthermore, NPM's “emphatic concern for greater cost efficiency tends to marginalize discussions of the content and quality of public services" that are crucial to innovation (Torfing 2013, 302).

A consistent theme across all these literatures is that there are alternatives to NPM approaches to promoting innovation in public services. Hartley et al. $(2013,821)$ point to different ways of thinking about innovation based on 'neo-Weberian' approaches, aimed at making state bureaucracies more responsive "through a combination of transformational leadership, institutional and organizational integration, trust-based management and increased responsiveness toward the demands from citizens". These strategies tend to rely upon inhouse innovation through strengthened inter-organizational and intra-organizational 
networks; and strategies to promote employee engagement and organizational entrepreneurship. Clearly, some of these concepts also fit well with NPM, reflecting a degree of fuzziness in the conceptualization of neo-Weberian innovation. Accordingly, given the lack of a "comprehensive doctrine delineating the precise content of the neo-Weberian state" (Hartley et al. 2013, 825), we have not fully operationalized neo-Weberian approaches in our innovation case study below - our analysis instead focused on the tensions between coexisting NPM-oriented and collaborative innovation themes.

An alternative and, for us, crucial approach focuses on collaborative innovation. For Sørensen and Torfing $(2011,849)$ collaborative innovation in public services can be defined as: "an intentional process that involves the generation and practical adoption and spread of new and creative ideas, which aim to produce a qualitative change in a specific context". It is a process that sees "two or more actors engage in a constructive management of differences in order to define common problems and develop joint solutions based on provisional agreements that may co-exist with disagreement and dissent..." (Hartley et al. 2013, 826). Collaborative innovation draws on network theory to suggest that co-operative networking is required to find multi-disciplinary solutions to complex policy problems (Hartley et al. 2013). There are also clear overlaps with theories of high involvement innovation in private enterprises (Bessant 2013) and certain forms of co-production that seek to deliver innovation towards more responsive public services (Clark et al. 2013). Finally, perhaps the clearest parallel between innovation debates and the broader public management literature relates to the shift towards post-NPM forms of organizing public services, and particularly emerging interest in cross-sectoral collaboration (Bryson et al. 2006, 2015) and a new public governance (NPG) based on inter-organizational networking (Osborne 2010). Sørensen and 
Torfing (2015) make an explicit connection between NPG and collaborative innovation based on sharing assets and ideas across public sector boundaries.

We again acknowledge that we are drawing upon, but adapting, themes from a literature that was initially primarily concerned with inter-organizational relations. We have developed these themes to provide a framing for an exploration of intra-organizational working between and across various managerial and employee groups. Yet, it seems appropriate to adapt themes from the discussion of 'NPM' and 'collaborative' approaches to innovation to a study of employees' experiences of a radical work and service redesign project. The extent of 'NPM' and alternative 'post-NPM' approaches to work organization in public services is an established area of study (Sørensen and Torfing 2015). However, while there has been widespread support for post-NPM, collaborative ways of managing people and public services, there remains debate about the extent to which the 'stickiness' of institutionalized NPM workplace practices constrains or creates tensions with collaboration (Dickinson and Sullivan 2014). And there is a clear synergy between studies of inter-organizational collaborative innovation and an emerging literature on the importance of collaborative work organization as a key theme in 'workplace innovation'. We now briefly make the connection with this literature.

\section{Collaborative innovation and work redesign in public organizations}

From the perspective of the research described below, an important benefit of a collaborative innovation approach is its acknowledgement of employees' potential joint-leadership role in driving innovation. Under NPM models of innovation, "the privileged role of public managers tends to exclude the important contribution of public employees" (Torfing 
2013, 302). Indeed, the NPM-influenced literature tends to downplay the idea of employees taking a leading role - Bason $(2010,131)$ acknowledges the "massive potential [for] employee involvement" in, but apparently not their leadership of, innovation.

Yet, we can see the case for collaborative public innovation as synergistic with emerging literatures on the value of 'workplace innovation' or 'employee-driven innovation' (EDI). OECD $(2010,6)$ research on workplace innovation has noted the specific challenges faced by public organizations "to adapt to changes in technology and in the demands of citizens", but also that these organizations are "characterized by higher levels of learning, problem-solving and task complexity", suggesting that employees, managers and other stakeholders are well placed to collaborate on service transformation. The same study acknowledges the potential for innovation from "the use of employee autonomy and discretion, supported by learning and training opportunities", reflecting the need "to put the organization of work more centrally in the analysis of innovation" (OECD 2010, 9).

This arguably reflects a broader shift in understandings of innovation, from a traditional view of product-driven or technology-driven change to one that acknowledges EDI as "embedded in everyday critical and reflective experiences and work practices, which in turn are often triggered by social interaction and exchange" (Kesting and Ulhøi 2010, 66). From this perspective, "employee learning at the workplace - in terms of new knowledge, expertise and problem-solving skills - constitutes the raw material for employee-driven innovation" (Høyrup et al. 2012, 3). A growing interest in workplace and employee-led innovation has informed numerous recent policy initiatives and research projects in EU states, as governments have sought new solutions to 'productivity puzzles' in the form of support for work redesign and job enrichment strategies designed to tap the innovative potential of 
employees (for a review, see European Commission 2014). Torfing and Triantafillou (2016, 71) chart how a parallel shift across many EU states has seen policymakers seek out new approaches to innovation "to solve intractable problems" and respond to "citizens who have growing expectations of the quality and availability of public services”. De Lancer Julnes $(2015,27)$, reviewing US evidence, concurs that "the desire to address intractable problems using collaborative arrangements" has driven new forms of public service networking designed to connect up employees' resources and energies in order to "increase the capacity of organizations". These shifts may be particularly visible in healthcare, where communities of practice that network professionals' complementary expertise have been identified as a potential source innovation in both inter-organizational and intra-organizational settings (Pattinson et al., 2016).

To summarize, there remains considerable controversy as to how best to conceptualize and evaluate NPM-oriented and alternative forms of innovation in public services. Accordingly, we have adapted and developed the themes identified by Torfing (2013) in order to explore employees' and managers' experiences of an innovative service and work redesign project.

\section{INSERT TABLE 1}

Table 1 contrasts collaborative and NPM-driven approaches across a number of dimensions. For example, adapting the ideas of organizational collaborative innovation and workplace innovation to our research, we might expect the role of employees in such redesign processes to be defined by the opportunity and motivation to collaborate on creative problem-solving projects outside of strictly defined job roles (Høyrup et al. 2012). While collaboration also forms a theme for NPM work redesign, there is an emphasis on teamworking as a route to 
'lean' efficiencies, with employees' actions directed by both 'customer' demands and performance indicators (Procter and Radnor 2014).

Torfing (2013) emphasizes the crucial role of 'boundary spanning' across organizations and networks in his work on organization-level innovation, but such capacities and roles can be as important within organizations and across different employee groups. There has been particular interest in the innovative potential of inter-disciplinary boundary spanning among professionals in public services - partly because of the perception that professional boundaries remain a barrier to innovation; partly because boundary-spanning roles seem to be important in delivering ‘joined-up’ services (Williams 2012).

Staying with intra-organizational relations, both the collaborative innovation and EDI literatures emphasize the crucial role of opportunities for transformative learning within and across teams and groups of employees. De Spiegelaere et al. (2014) note that numerous studies have found a relationship between collaboration within multi-skilled teams and innovativeness. As noted above, the EDI literature more generally sees workplace innovation as "a reflexive process, grounded in continuing reflection, learning and... involving employees and managers at all levels" (European Commission 2014, 69). So EDI eschews the idea of the 'hero innovator' (i.e. that public service innovation tends to be driven by a few innovative people) in favour of an emphasis on the need to support structures for collaboration and learning that open up new opportunities to innovate (Sørensen and Torfing, 2015). NPM ideas around workplace transformation also emphasize teamwork and multiskilling (Procter and Radnor 2014), but intra-organizational cooperation may be constrained and directed by the priorities of key performance indicators and standard operating procedures. 
The last two of our themes developed from Torfing's (2013) discussion focus on the role of managers. For Torfing $(2013,309)$, collaborative innovation requires managers (in strategic roles and at the line) to partner with employees to "facilitate and lead collaboration to spur innovation". This is a clear divergence from NPM characterizations of the entrepreneurial manager driving strategic change through a combination of transformational leadership and 'best practice' management techniques. Under collaborative innovation, public managers will arguably be required to "relinquish technocratic perceptions that only they have the professional expertise to make sound decisions [instead] orchestrating collaborative arenas that harvest ideas and practices from a range of innovators" (Hartley et al. 2013, 827).

We might expect related distinctions to play out with regards to formal management systems deployed by managers - pervasive performance monitoring and management by objectives are arguably the defining features of NPM-informed HRM (Carter et al. 2013); but systems and practices for encouraging collaborative innovation might be more likely to reflect the outcomes of a multi-stakeholder consensus around shared objectives and mutual gains. Intraorganizational collaborative innovation is likely to be characterized by inter-dependency where teams and workers see themselves as equal (and necessary) partners in achieving shared or complementary goals.

These key themes around NPM-oriented and collaborative forms of innovation in public services provide a framework for our discussion of an innovation in service and work redesign in the NHS in Scotland. We now turn to the context and methods for our research.

\section{Context and methods}


This part of the article describes the organizational and policy context for our research, before turning to an explanation of our research methods.

\section{Context for the research}

This research was located within a large Health Board that is responsible for funding and managing healthcare (including pharmacy provision) in one area of NHS Scotland Scotland's national public health provider, which employs more than 150,000 staff, and at the time of the research accounted for $£ 11.1$ billion of public spending. In 2008, the area Health Board in question approved a major pharmacy redesign program with objectives including to: redefine hospital pharmacy services around 'patients' own medicine', through new systems to store securely and manage patients' medication; and measures to redesign and automate medicine distribution, in order to release pharmacy staff to undertake near-patient tasks as part of integrated clinical teams. The aim was to use to new technologies to support wardbased services to better manage patients' medicines at bedside - an initiative that we will refer to as 'MyMeds' hereafter.

The introduction of new robotics technologies in the pharmacy distribution function was an integral part of this redesign. A key element in the implementation of the redesign program was the construction of a new Distribution Centre (DC) to replace eleven different in-hospital pharmacies. The DC is now the single facility responsible for the procurement and distribution of medicines to replenish ward and site pharmacy stocks for all hospitals and clinics in the Health Board area (approximately 4,000 destinations). Aligned to this automation project was a major organizational change program with significant implications 
for jobs, work organization and employees' experiences. This involved most employees being moved out of dedicated dispensaries at hospital sites. Instead, pharmacists and many technicians were moved nearer the patient to smaller ward-based sites. Other staff were redeployed to the centralized DC. A key element of the DC's work is facilitated by robots that store, gather and distribute medicines in response to replenishment orders on a '24-7' basis. Within the DC, nine robots are programed to work in tandem as an integrated storage and distribution system. DC employees manage, maintain and facilitate the automated distribution processes. Finally, a minority of staff were retained to deliver the remaining support services provided by hospital dispensaries. We note below that the use of robotics to redesign pharmacy services may have been framed by a number of different policy and reform agendas, including strong government support for lean management in public services. However, it was clear from our interviews with senior clinical pharmacists and managers leading the Health Board's services that it was their decision and initiative to seek funding for this project. The view among clinical leaders was that there was evidence of improved efficiency and patient care where robotics was used to free clinical pharmacists to engage in patient-facing work.

A range of parallel rationales can be identified as informing the Health Board management's decision to take forward the pharmacy redesign program. First, there was clearly a genuine interest in promoting person-centred clinical pharmacy services 'nearer the patient', in line with high-level strategies. The Scottish Government's $(2013,2)$ strategy for NHS pharmaceutical care places a strong emphasis on empowering both patients and pharmacy professionals, with a commitment to "working in collaborative partnerships with other health and social care professionals... using the clinical skills of the pharmacist to their full potential". The Scottish Government argues that redesigning work organization is essential to 
making this happen: "If patients are to fully benefit from the clinical skills of hospital pharmacists, then traditional ways of working must be redesigned so that hospital pharmacy services become more patient-focused" (Scottish Executive 2006, 21).

However, the redesign program also reflected some of the key assumptions of NPM. For example, the redesign program fitted with a broader agenda emphasizing the need to evidence in quantitative terms (and perhaps even monetize) the contribution of NHS pharmacy services to clinical outcomes. NPM themes around cost control and standardizing and quantifying performance were clearly reflected in the underlying business case for the redesign. Finally, the imposition of lean staffing and processes were a consistent source of tension between staff and managers involved in the redesign (Lindsay et al. 2014). Nevertheless, as we see, many of the roles, behaviours and practices that made the redesign project work digressed from NPM norms, and were more representative of collaborative innovation as discussed above.

Despite these competing rationales for the redesign, what is clear is that the program drove through major - and innovative - change in how services were delivered and work was organized. The redesign project sought to change fundamentally how and where pharmacy services were delivered and experienced; it promised new collaborative and co-productive relationships between occupational groups, patients and stakeholders; it produced completely new operational forms built around a substantial investment in cutting-edge technologies; and it involved the creation of new job roles and ways of working. This project therefore delivered on a number of forms of public sector innovation discussed by Bekkers et al. (2011, 16), including 'service', 'process' and 'technological' innovations, but crucially for us 
'organizational' innovation - "the creation of new organizational forms, the introduction of new management methods and techniques, and new working methods".

The remainder of this article uses debates on NPM and collaborative approaches to innovation as a way of exploring employees' and managers' experiences and actions in driving public sector innovation in this case. We have reason to believe that these themes may be helpful in exploring experiences of innovation in the NHS in Scotland. Reflecting on Hartley et al.'s (2013) discussion of NPM, neo-Weberian and collaborative models, Fairman (2013, 831) notes that the NHS in England demonstrates "strong elements of the first two of the organizational and leadership approaches to innovation", but also that there are elements of collaborative innovation in the emergence of recent regional partnership-working.

Similarly, these overlapping, at times complementary and at times contradictory themes can be detected in the distinctive delivery of NHS services in Scotland. The regional Health Board structure that provided governance context for our research provides a stark contrast with more fragmented and market-led forms of NHS organization in England (with NHS Scotland's governance structures arguably providing a more conducive environment for collaboration). Nevertheless, some NPM themes such as lean management have been enthusiastically embraced by managers and policymakers (Lindsay et al. 2014). Finally, while the concept of collaborative innovation has not, to our knowledge, previously been applied to the NHS in Scotland, its key tenets of employee engagement and inter-professional collaboration were, as we will see below, fundamental to the successes of this project.

\section{Methods}


Our research was a qualitative study, based on interviews with employees, managers and other stakeholders, particularly focusing on experiences of the redesign program and impacts on work and working life. The employee-focused element of the research involved interviews with 36 staff, which included six pharmacists, sixteen pharmacy technicians and fourteen support workers. NHS pharmacists are clinical professionals who advise medical and nursing staff, and support patients to manage their medicines to ensure optimal treatment. Pharmacists are qualified at Masters degree level/equivalent and are able to undertake additional training in order to allow them to prescribe medicines for specific conditions. Pharmacy technicians execute tasks such as assembling medicines, and at entry level require a General Pharmacy Council qualification that equates to UK Vocational Qualification Level 3. With additional training, technicians can progress to senior roles that might involve - for example - performing final accuracy checks on dispensed medicines. Pharmacy support workers are entry-level staff who are trained to assist pharmacists and technicians with administrative and IT-based activities.

As noted above, the redesign program and linked MyMeds project sought to re-center the work of NHS pharmacists (many of whom had previously been based in hospital dispensaries) on the delivery of ward-based, patient-facing services. To support these changes, pharmacy technicians were redeployed to three main roles: the delivery of MyMeds at ward-level (arranging prescriptions for, and gathering information from, patients; and supporting the work of ward-based pharmacists); supervising the large-scale distribution function at the DC; and maintaining hospital dispensaries, which continued to provide prescriptions for out-patients and a hospital-level link in the supply chain between wards and the DC. As with the technicians, support workers were redeployed between the wards, the DC and hospital dispensaries, in support roles including: data entry for medicines orders; 
organising, storing and checking deliveries; and, in some cases, assisting in MyMeds services at ward-level.

The sample comprised 25 women and 11 men. Participants were aged between 25 and 65 (with a mean age of 41) and had worked for the NHS for between four and 40 years. The ratio of full-time to part-time employees was 5:1. One-to-one, semi-structured interviews lasting 45-120 minutes were recorded, transcribed, coded and analysed using QSR NVIVO 10.0. A complementary 'key stakeholder' element of the research involved ten in-depth interviews with representatives of senior management, employee partnership groups and trade unions. The aims of our interviews (and therefore key themes in the interview schedule) were: to enable managers and employees to define their roles in, and understanding of, the innovation process; to explore the interaction of employees with each other and their managers in managing and learning during the innovation process; and to identify changes in workplace practices and employees' experiences over the lifetime of the innovation process. These areas of discussion generated qualitative data that we analysed thematically drawing on the literature on collaborative and NPM-driven innovation discussed above.

\section{Findings}

This part of the article uses the themes discussed in Table 1 to frame a discussion of the findings of our research on employees' and managers' experiences of the redesign program.

\section{The role of employees: collaborators in creative problem solving?}


We have argued that for collaborative innovation to succeed in driving workplace change, employees must be enabled to take action beyond the specific constraints of their roles within lean teams, and to engage in problem solving in flexible and responsive ways. There was clear evidence of exactly such collaborative activity in this case. For example, employees and managers recalled how their information sharing on flaws in the initial robotics hardware had driven a significant technical recalibration of the DC systems. In short, the causes of suboptimal performance of robotics systems was diagnosed by managers and employees, resulting in continuing redesign changes to the distribution technology.

Similarly, both employees and managers spoke of collaboration to reorder shift patterns to maximize efficiency. Among DC staff and managers, it became clear that 24/7 operation (and therefore the establishment of a night shift) was necessary to maintain the functioning of the robotics distribution systems. Both employee and manager groups interviewed for our research claimed to have initiated the idea of a nightshift (which was eventually established when some existing employees agreed to work nights) but both groups acknowledged that collaboration had been necessary to bring these changes to work organization to fruition. This suggests a degree of ceding of leadership of innovation from managers to employees that previous international studies have found to be important to achieving success in public service reform programs (Sørensen and Torfing 2015). Senior managers acknowledged that the establishment of the nightshift had been a collaborative effort of employees and managers. There was also an acceptance that the commitment of employees to delivering high quality services was important to explaining why many had agreed, for the first time in their working lives, to work nights, and why employees were willing to support each other to ensure that this aspect of the redesign worked. 
"They [DC team] came up with the night shift idea and when it worked, we had a member, one of the night shift team, couldn't cope with nightshift, which is not unexpected. And it looked as if it might have to fold, and they all volunteered to do it, to keep it going. You wouldn't get that anywhere else, nowhere else." Senior Manager

It is important to acknowledge that there remained concerns regarding experiences of work intensification among some employees. The need to achieve 'discharge deadlines' (i.e. ensuring that medicines were delivered in time for patients' discharge from hospital) produced intermittent moments of intense pressure, and more generally lean staffing had produced stress in terms of workload management and the pace of work. Accordingly, the employee as 'lean team member' whose work is defined in response to internal and external customer demands - which we suggest above is characteristic of NPM-influenced approaches to innovation (Procter and Radnor 2014) - was partly reflected in the experiences of interviewees. Less predictable, from the perspective of the NPM literature, was the capacity of employees and managers to collaborate and thus improve the implementation of change.

\section{Intra-organizational relations: transformational learning and inter-disciplinary boundary spanning}

A second indicator of collaborative innovation identified in Table 1 relates to intraorganizational relations, with advocates of post-NPM approaches arguing that public service workplaces can and should allow for 'transformational learning' - ways of working that allow practice-sharing and learning across job roles. Supporters of lean management and other NPM-oriented workplace reforms also make claims around new learning (Procter and 
Radnor 2014), but there is counter-evidence of deskilling and standardization in some cases (Carter et al. 2013). In our case, some employees enthusiastically reported new opportunities for transformational learning. Support workers deployed to wards valued working closer to pharmacists and patients. These interviewees reported increased task variety and opportunities to learn from - and support - a broader range of professional functions.

"I prefer to be up on the wards ... because every day is different when you're up on the wards ... You're meeting new people. And you're finding out different things every day, new things that you didn't know. Whereas when you were down here [in the central hospital dispensary] you were just doing the same things every day.”

Hospital Level 3 Support Worker

Pharmacy technicians working on hospital wards similarly largely supported the idea that opportunities for transformational learning had been generated by the redesign project. They gave examples of improved access to more formalized training, more varied work and better skills utilization. However, in the case of both technicians and support workers, there was something of a polarization in experiences of new learning. Those deployed to the DC reported undertaking additional training, but this focused almost entirely on servicing the robotics technologies. Some were frustrated at limited opportunities for rotation and learning within hospital environments, and feared that their skills would become narrower and/or outdated. 
"I need to go back to the sites and learn again, because there's so many things

change ... there 'll be loads of things changed since I've left there two years

ago..."

DC Level 4 Technician

Support workers based at the DC similarly reported a narrowing of learning opportunities with training focused on a set of relatively standardized functions built around robotics distribution - and complained that lean staffing and work intensification had at any rate reduced the time available for skills development. It is important to emphasize here that work intensification - and the associated stress - was seen as an outcome of inevitably tight deadlines and lean staffing, but not as a side-effect of inappropriate performance management systems. Deadlines and work targets (which often related to ensuring that the right medicines were prepared for patients upon discharge) were seen as appropriate and in line with the principles of high-quality patient care (Lindsay et al. 2014).

DC technicians tended to share the view that there was little time for learning as a result of the removal of staffing buffers. And technicians across all settings raised concerns that lean staffing and a broader recruitment freeze (combined with low turnover rates in senior positions) meant that there were few opportunities for progression.

'I don't feel there's anything, because they've cut back so many... There's no progression, there's no aim. There's nothing to aim for, other than a sideways move to, maybe, another hospital."

Hospital Level 5 Technician 
As noted above, advocates of collaborative innovation also point to the importance of interdisciplinary boundary spanning as a route to new and better ways of working (Williams 2012). There were again mixed experiences among our interviewees. Clearly, the physical relocation of some pharmacy technicians to hospital wards was seen as providing opportunities for these employees to engage in practice-sharing and collaboration across established professional boundaries. Perhaps as importantly for senior management, the upskilling of pharmacy technicians to execute 'final release' procedures for prescribed medicines had the effect of "freeing pharmacists to be more clinical" (Senior Manager) released from these important (but still largely administrative) duties, pharmacists had the opportunity to focus more on the clinical aspects of patient-based care, supporting medical and nursing staff and collaborating across professional boundaries. There was strong support for the redesign program among the majority of pharmacists who saw benefits in their participation in inter-disciplinary teamworking, and described progress towards more integrated and inter-dependent ways of working with other professions (Gilburt 2016).

\footnotetext{
"You have to obviously integrate with the multidisciplinary team so you're working with consultants, senior doctors, junior doctors, nursing staff, dietician OT's, physios the whole lot. So you have to be aware of what everyone's role is and their level of input can be..."
}

Hospital Pharmacist

The redesign project also saw some pharmacy technicians and (to a lesser extent) support workers redeployed to hospital wards - again, the reactions of these employees were generally positive in relation to opportunities for inter-disciplinary working. But other support workers and technicians redeployed to the DC were less likely to report opportunities 
for inter-disciplinary working - indeed opportunities for 'rotation' between different areas of work and teams had been curtailed for these employees, some of whom saw themselves as restricted to 'distribution' or 'warehouse' roles. Some of our interviewees based at the DC expressed frustration at fewer opportunities for inter-disciplinary working across professional boundaries, and feared that they would experience deskilling as a result. Thus, for some employees, intra-organizational engagement was arguably defined by NPM norms whereby day-to-day teamworking was framed by standard operating procedures and repetitive tasks. The findings above point to polarized experiences of this technology-driven redesign project - some employees were able to harness robotics to access new opportunities for autonomy, control and learning; others felt controlled by new technologies, identifying additional constraints on job roles and learning. An important lesson might be that managers and employees need to work together to build a shared and realistic conception of the potential outcomes and limitations of innovation programs "to avoid being disappointed with the results” (De Lancer Julnes, 2015, 27).

\section{The roles of managers and management systems}

The importance of management support for innovation has been highlighted by a number of international studies of innovation in healthcare organizations (for a review, see Örtenblad et al. 2016). Advocates of collaborative innovation envisage managers as facilitators of collective collaboration, a role which might be contrasted with top-down, cost-focused change management (Sørensen and Torfing 2015). Managers contributing to our research were keen to highlight their engagement of staff in the planning of the redesign project management-employee focus groups had informed the 'business case', and progress was disseminated via an inter-disciplinary steering group and 'roadshow' events that sought to 
engage staff at all levels. But the redesign was seen by some staff as driven from the topdown. Pharmacy technicians suggested that their feedback was rarely actioned. For some, 'listening events' amounted to little more than top-down announcements of pre-planned, management-driven changes.

"...Basically they had their vision, and that was the vision and that was what was going to happen, and I feel that there was a lot of ticking boxes: you need to have partnership involved, you need to have OD, you need to have HR. So they had their vision and that's what they wanted and that's what we had to provide."

Hospital Level 5 Technician

We have noted elsewhere that the claims made by managers at the outset of the redesign project - in terms of the inclusion of employees at all levels in decision-making - were not fully realized, something acknowledged by managers themselves (Lindsay et al. 2014). Accordingly, their role may be seen as more closely aligned with the principles of NPMdriven innovation - applying technology-driven solutions to drive down costs and seeking the compliance of 'lean teams' within employee groups.

Despite these apparent limits to post-NPM approaches to public service innovation, we found mixed evidence of dominant NPM themes in the role of management systems shaping change. As discussed above, the principles of lean staffing certainly informed aspects of the redesign project, but the enforcement of top-down performance management systems predicted by the literature to be a recurring component of NPM-driven innovation - was not identified as a key reform theme by employees or managers. Employees across all skill levels did report having to working to tight deadlines, in that medicines had to be distributed in 
accordance with planned patient discharge times. However, whereas some studies of NPMdriven innovation have identified intrusive and unhelpful forms of performance management as a side-effect, our interviewees generally saw discharge deadlines as an essential and relevant target, in line with the principles of high quality patient care. Of course, it needs to be acknowledged that the context within which these essential deadlines had to be met was one of consistent resource and staffing shortages and therefore a normalization of work intensification.

\section{Discussion}

Hartley et al. (2013) and Torfing (2013) have made a convincing case that collaborative innovation can offer an alternative to NPM-driven innovation strategies in the public sector, and more accurately reflects post-NPM thinking and practice in many public organizations. Our starting point for this article was to draw on the literature on collaborative innovation and NPM-driven innovation to frame a discussion of our research on employees' and managers' experiences of an innovative service and work redesign program in one area of the NHS. Our study offers, albeit limited, insights on employees' lived experiences of innovation in work organization - this is of value given that too much research on public sector innovation has neglected to comment on impacts upon those delivering services (De Vries et al. 2016).

We found that collaborative innovation does indeed capture the sort of roles, relationships and systems that were important to driving this major innovation project. Elements of collaborative innovation described in Table 1 were reflected in employee-manager collaboration to solve problems in the workplace and in some employees' experiences of mutual learning and inter-disciplinary boundary spanning. We were also able to explore the 
limits to collaborative innovation, with contrasting experiences for employees redeployed 'nearer the patient' and 'nearer to technology'. For some among the latter, there were fewer opportunities for learning and collaboration, and instead negative experiences of standardization and work intensification. These negative experiences of technology-enabled job redesign chime with a broader international literature that sees automation as problematic - with "a wave of concern about the implications of robotics" a specific theme (Gallie 2017, 227) - and as contributing to jobs polarization and the relative decline of medium-skilled jobs (Autor 2010). We also identified some strong legacies of NPM in some top-down leadership and management practices, and in an all-encompassing commitment to lean staffing. An important finding is therefore that both collaborative innovation and NPM elements coexisted in this hybrid innovation process, reflecting the 'stickiness' of institutionalized public management practices. Researching innovation in public service workplaces requires an acknowledgement of how distinctive but overlapping understandings of, and approaches to, transforming public services are experienced by employees.

\section{Conclusions}

While NPM-driven models continue to influence public service reform strategies in Scotland, elsewhere in the UK and beyond, our research suggests that collaborative approaches can find (and have found) expression in attempts to develop more effective ways of working. Many of the positive outcomes from the redesign project were delivered by collaborative innovation practices that support shared problem-solving in job roles and inter-disciplinary boundary spanning in work organization. Crucially, while the impacts on employees' job quality were mixed, those working 'nearer the patient', who reported largely positive experiences, also pointed to the benefits of an exercise in work redesign that prioritized inter-disciplinary 
learning and collaboration (see also Christensen et al. 2017). Thus, our research adds to a growing international literature across diverse public management regimes that points to the potential benefits of collaborative networking for innovation among public service employees, in order to join up ideas, expertise and energies to drive change (for reviews of evidence, see De Lancer Julnes 2015 and Sørensen and Torfing 2015). However, there is also a need for further research on the problems of work redesign programs that flatten occupational structures and limit opportunities for progression for some employees. These changes in work organization may have long-term implications for the retention of public service professionals. More broadly, there is a need for further research on the specific workplace practices and forms of work organization that support collaborative innovation in different public service contexts.

The demands of an increasingly complex population of public service users and the continuing context of economic austerity have presented a unique set of challenges for policymakers and public sector managers. There is an urgent need for innovation in work organization and service delivery. Our work adds to a body of literature that argues for further evidence on the potential added value of collaborative innovation in the public sector. Redesigning public services - in healthcare or other sectors - in ways that unleash the potential of inter-disciplinary collaboration and mutual learning may offer a route to more efficient and effective services and better jobs for public employees. 


\section{References}

Ansell, Christopher, and Jacob Torfing. 2014. Public Innovation Through Collaboration and Design. London: Routledge.

Autor, David. 2010. The Polarization of Job Opportunities in the US Job Market.

Washington, DC: Center for American Progress.

Bason, Christian. 2010. Leading Public Sector Innovation. Bristol: Policy Press.

Bekkers, Victor, Jurian Edelenbos, and Bram Steijn. 2011. Linking Innovation to the Public Sector: Contexts, Concepts and Challenges. In Innovation in the Public Sector: Linking Capacity and Leadership, edited by Victor Bekkers, Jurian Edelenbos, and Bram Steijn, 3-32. Basingstoke: Palgrave Macmillan.

Bertot, John, Elsa Estevez, and Tomasz Janowski. 2016. Universal and Contextualized Public Services: Digital Public Service Innovation Framework. Government Information Quarterly 33(2): 211-222.

Bessant, John. 2013. Innovation in the $21^{\text {st }}$ Century. Exeter: University of Exeter.

Bryson, John M., Barbara C. Crosby, and Melissa Middleton Stone. 2006. The Design and Implementation of Cross-Sector Collaborations: Propositions from the Literature. Public Administration Review 66: 44-55.

Bryson, John M., Barbara C. Crosby, and Melissa Middleton Stone. 2015. Designing and Implementing Cross-sector Collaborations: Needed and Challenging. Public Administration Review 75(5): 647-663.

Carter, Bob, Andy Danford, Debra Howcroft, Helen Richardson, Andrew Smith, and Phil Taylor. 2013. Stressed Out of My Box: Employee Experience of Lean Working and 
Occupational Ill-health in Clerical Work in the UK Public Sector. Work, Employment \& Society 27(5): 747-767.

Christensen, Robert K., Laurie Paarlberg, and James L. Perry. 2017. Public Service Motivation Research: Lessons for Practice. Public Administration Review 77(4): 529-542. Clark, Benjamin Y., Jeffrey L. Brudney, and Sung-Gheel Jang. 2013. Coproduction of Government Services and the New Information Technology: Investigating the Distributional Biases. Public Administration Review 73(5): 687-701.

De Lancer Julnes, Patria. 2015. The Study of Innovation: State of the Art and Framework for Analysis. In Innovation in the Public and Nonprofit Sectors: A Public Solutions Handbook, edited by Patria De Lancer Julnes, and Ed Gibson, 12-32. London: Routledge. De Spiegelaere, Stan, Guy Van Gyes, and Geert Van Hootegem. 2014. Labour Flexibility and Innovation, Complementary or Concurrent Strategies? A Review of the Literature. Economic and Industrial Democracy 35(4): 653-666.

De Vries, Hanna, Victor Bekkers, and Lars Tummers. 2016. Innovation in the Public Sector: A Systematic Review and Future Research Agenda. Public Administration 94 (1): 146166.

Dickinson, Helen, and Helen Sullivan. 2014. Towards a General Theory of Collaborative Performance: The Importance of Efficacy and Agency. Public Administration 92(1): 161177.

European Commission. 2014. State of the Innovation Union. Luxembourg: European Commission.

Fairman, Steve. 2013. Commentary: Collaborative Governance for Innovation in the National Health Service: Early Reflections on the Development of Academic Health Science Networks. Public Administration Review 73(6): 831-832. 
Gallie, Duncan. 2017. The Quality of Work in a Changing Labour Market. Social Policy \& Administration 51(2): 226-243.

Gilburt, Helen. 2016. Supporting Integration Through New Roles and Working Across Boundaries. London: King's Fund.

Hartley, Jean, Eva Sørensen, and Jacob Torfing. 2013. Collaborative Innovation: A Viable Alternative to Market Competition and Organizational Entrepreneurship. Public Administration Review 73(6): 821-830.

Høyrup, Steen, Maria Bonnafous-Boucher, Cathrine Hasse, Maja Lotz, and Kirsten Møller. 2012. Employee-Driven Innovation: A New Approach. Basingstoke: Palgrave Macmillan. Kesting, Peter, and John Parm Ulhøi. 2010. Employee-Driven Innovation: Extending the License to Foster Innovation. Management Decision 48(1): 65-84.

Lindsay, Colin, Johanna Commander, Patricia Findlay, Marion Bennie, Emma Corcoran Dunlop, and Robert Van Der Meer. 2014. Lean, New Technologies and Employment in Public Health Services: Employees’ Experiences in the National Health Service. International Journal of Human Resource Management 25(21): 2941-2956. Mazzucato, Mariana. 2013. The Entrepreneurial State. London: Anthem Press. OECD. 2010. Innovative Workplaces. Paris: OECD.

Örtenblad, Anders, Carina Abrahamson Löfström, and Rod Sheaff. 2016. Management Innovations in Healthcare Organizations. London: Routledge.

Osborne, Stephen P. 2010. The New Public Governance?. London: Routledge.

Pattinson, Steven, David Preece, and Patrick Dawson. 2016. In Search of Innovative Capabilities of Communities of Practice: A Systematic Review and Typology for Future Research. Management Learning 47(5): 506-524.

Perry, James L., and Kenneth Kraemer. 1983. Public Management: Public and Private Perspectives. Palo Alto: Mayfield. 
Pollitt, Christopher. 2011. Innovation in the Public Sector: An Introductory Overview. In Innovation in the Public Sector: Linking Capacity and Leadership, edited by Victor Bekkers, Jurian Edelenbos, and Bram Steijn, 35-43. Basingstoke: Palgrave Macmillan. Procter Stephen, and Zoe Radnor. 2014. Teamworking under Lean in UK Public Services: Lean Teams and Team Targets in Her Majesty's Revenue \& Customs (HMRC). International Journal of Human Resource Management 25(21): 2978-2995.

Scottish Executive. 2006. The Right Medicine: A Strategy for Pharmaceutical Care in Scotland. Edinburgh: Scottish Executive.

Scottish Government. 2013. Prescription for Excellence: A Vision and Action Plan for the Right Pharmaceutical Care through Integrated Partnerships and Innovation. Edinburgh: Scottish Government.

Sørensen, Eva, and Jacob Torfing. 2011. Enhancing Collaborative Innovation in the Public Sector. Administration and Society 43(8): 842-868.

Sørensen, Eva, and Jacob Torfing. 2015. Enhancing Public Innovation through Collaboration, Leadership and New Public Governance. In New Frontiers in Social Innovation Research, edited by Alex Nicholls, Julie Simon, and Madeleine Gabriel, 145-169. Basingstoke: Palgrave Macmillan.

Torfing, Jacob. 2013. Collaborative Innovation in the Public Sector. In Handbook of Innovation in Public Services, edited by Stephen P. Osborne and Louise Brown, 301-316. Cheltenham: Edward Elgar.

Torfing, Jacob, and Peter Triantafillou. 2016. Enhancing Public Innovation by Transforming Governance. Cambridge: Cambridge University Press.

Williams, Paul. 2012. Collaboration in Public Policy and Practice. Bristol: Policy Press. 
Table 1 Themes in public service innovation, with reference to employees' and managers' experiences in the workplace

\begin{tabular}{|c|c|c|}
\hline & Collaborative innovation & NPM-driven innovation \\
\hline Role of employees & $\begin{array}{l}\text { - Collaborators in creative } \\
\text { problem-solving }\end{array}$ & $\begin{array}{l}\text { - Members of 'lean' teams } \\
\text { responsive to customers }\end{array}$ \\
\hline $\begin{array}{l}\text { Defining features of } \\
\text { intra-organizational } \\
\text { relations }\end{array}$ & $\begin{array}{l}\text { - Transformative workplace } \\
\text { learning } \\
\text { - Inter-disciplinary boundary } \\
\text { spanning }\end{array}$ & $\begin{array}{l}\text { - Co-operation for achieving } \\
\text { team KPIs } \\
\text { - Consistency of team } \\
\text { performance in line with } \\
\text { standard operating } \\
\text { procedures }\end{array}$ \\
\hline Role of managers & $\begin{array}{l}\text { Facilitate and lead } \\
\text { collaboration to spur } \\
\text { innovation }\end{array}$ & $\begin{array}{l}\text { Drive strategic change and } \\
\text { efficiency from top-down }\end{array}$ \\
\hline Management systems & $\begin{array}{l}\text { Inter-dependent teamworking } \\
\text { achieved through workplace } \\
\text { collaboration }\end{array}$ & $\begin{array}{l}\text { - Management by objectives } \\
\text { - Individualized performance } \\
\text { management }\end{array}$ \\
\hline
\end{tabular}

